\title{
Ionosphere Electron Temperature Measurements and Their Implications
}

\author{
L. H. Brace and N. W. Spencer \\ Goddard Space Flight Center, Grcenbelt, Maryland \\ G. R. Carignan \\ Space Physics Research Laboratory \\ Department of Electrical Engineering \\ Universily of Michigan, Ann Arbor
}

\begin{abstract}
Electron temperature and ion density data, reported earlier in preliminary form, are reviewed in terms of their consistency with recent theories regarding thermal equilibrium in the daytime ionosphere. On the basis of these daytime data and the ionosphere theory, wo conclude that solar extreme ultraviolet radiation (EUV) is the dominant heat source in the quiet midlatitude ionospherc. This conclusion is suggested by the agreement between the electron temperature profiles mensured under these conditions and theoretically predicted profiles based on EUV radiation as the only hent souree. Mensurements in the disturbed midlatitude and auroral zone ionospheres suggest that, although EUV remains the dominant heat source for electrons in the $F_{1}$ region, an additional heat source is effective in the $E$ and $F_{3}$ regions. Its effect is to extend the region of thermal nonequilibrium both upward into the upper $F$ region and downward into the $E$ region. The results of a more recent flight in the nighttime ionosphere are presented and discussed. A horizontal gradient in clectron temperature found in the nighttime ionosphere is believed too abrupt to permit $\Omega$ similar gradient in the gas temperature and thus indicates that small but variable degrees of thermal nonequilibrium ean exist in the nighttime ionosphere. This is believed to be because of particle fluxes whose heating effects are enlanced by the low values of electron density existing in the nighttime $F$ region.
\end{abstract}

\section{INTRODUCTION}

The solar encrgy incident upon the earth's atmosphere in various forms (extreme ultraviolet, $\mathrm{X}$ ray, corpuscular) ionizes neutral particles in the thermosphere and thereby generates electrons having energies of tens of electron volts. Most of this cnergy is lost by inelastic collisions with the neutral particles, but the significant amount remaining after the last inclastic collision (approximately $2 \mathrm{ev}$ ) is rapidly shared by clastic collisions with the ambient electrons. Since the ambient electrons represent only a minority constituent of the ionosphere, this tends to raise the electron temperature above the gas temperature and produces a degree of thermal nonequilibrium in the altitude region where these processes are important. On the basis of these considerations, several investigators [Hanson and Johnson, 1961; Hanson, 1962; Dalgarno et al., 1962] have calculated the degree of noncquilibrium to be expected because of solar extreme ultraviolet (EUV) alone. Though their models of electron temperature differ in detail, all show that the absorption of EUV should cause the electron temperature to exceed the gas temperature between approximately 150 and $350 \mathrm{~km}$ in the quiet midday ionosphere. Their results, to be shown later, indicate that the $T_{r} / T_{\text {o }}$ ratio reachins values of 1.5 to 2 (between 150 and $350 \mathrm{~km}$ ), depending on the actual energy transfer mechanisms occurring there, and that thermal equilibrium is probably re-cstnblished above $350 \mathrm{~km}$. It is important to note that these authors have not considered the effects of other heat sources such as solar X radiation and corpuscular radiation which may bo of great importance in the disturbed or higherlatitude ionosphere and are probably significant even under quiet conditions at midlatitudes.

Experimental data concerning thermal equilibrium are conflicting. Evans [1962] has recently reported radar backscatter measurements indicating that the electron temperature above $300 \mathrm{~km}$ at midday normally exceeds the ion (and presumably neutral) temperature by a factor of 
1.6. Hanson and McKibbin [1961], Jackson and Bauer [1961], Brace et al. [1962], and others have, by assuming thermal equilibrium, used the scale-height concept to interpret rocket measurements of electron or ion concentration in the upper $F$ region in terms of atmospheric temperature. The consistency of these data with temperatures derived indirectly from satellite drag studies has been cited as partial justification for the assumption of thermal equilibrium [Bauer and Bourdeau, 1962].

In a recent paper Spencer et al. [1962] reported the data from a series of four daytime direct measurements of electron temperature in the $E$ and $F$ regions. These data confirmed that the electron temperature exceeds the generally accepted values of neutral particle temperature in the $F_{1}$ region, as had been predicted earlier by Hanson and Johnson [1961] and later by Hanson [1962] and Dalgarno et al. [1962]. However, only the single flight of this series that was made under quiet ionospheric conditions at Wallops Island showed the negative temperature gradient in the $F_{s}$ region that would be required to permit a return to thermal equilibrium there. The other three measurements of the series, including one in a disturbed ionosphere above Wallops Island and two in the auroral zone ionosphere (Ft. Churchill), indicated that the region of nonequilibrium extended to more than $400 \mathrm{~km}$ with generally increasing temperature above the $F_{2}$ maximum. These data tend to support Evans' results.

Unfortunately there exist too few measurements of electron temperature in the 150- to $450-\mathrm{km}$ altitude range to permit us to decide which electron temperature profile is normal: the 'quiet' ionosphere with its apparently wellbehaved region of thermal nonequilibrium between 150 and $350 \mathrm{~km}$, or the 'disturbed' ionosphere in which nonequilibrium extends down into the $E$ region and well into the upper $F$ region.

Since our earlier paper, in which preliminary data from NASA 6.03 and NASA 6.04 were presented, the analysis of data from these Wallops Island flights has been completed, enabling us to confirm our earlier conclusions about thermal equilibrium in the daytime ionosphere. In addition, a subsequent nighttime measurement at Wallops Island has been carried out and the data analyzed. It is the purpose of this paper to present final data from the earlier flights, ns well as data from the more recent nighttime flight, and to interpret the results of the entire flight series in terms of their consistency with certain aspects of ionosphere theory that have recently been reported. Emphasis will be on the

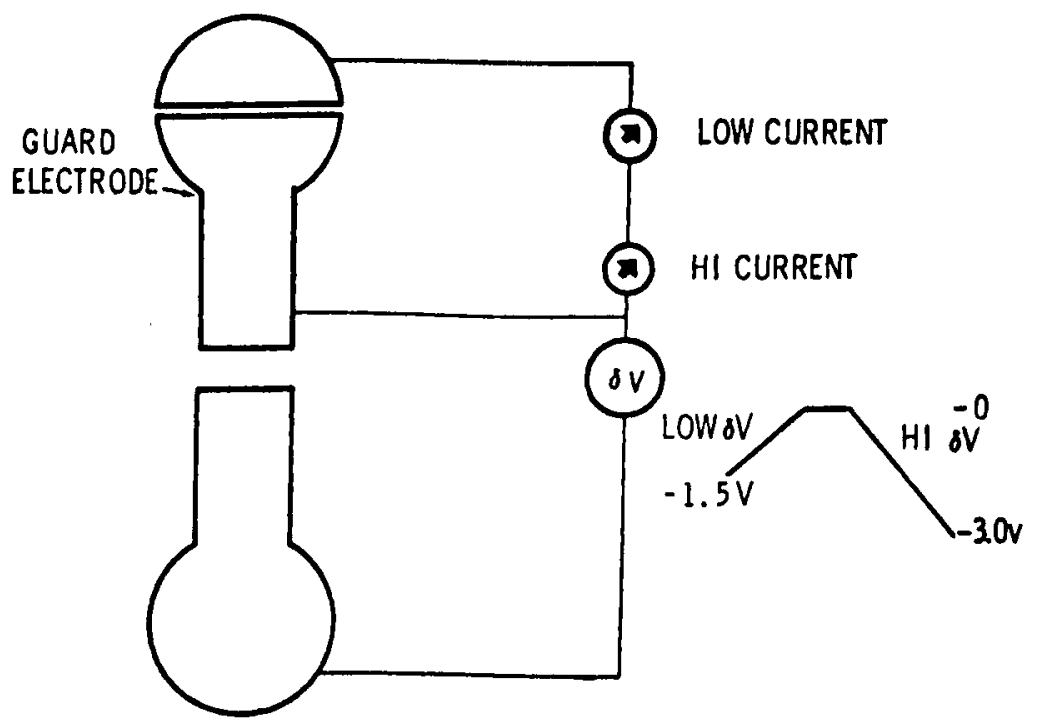

Fig. 1. The measurement system employed in the Dumbbell experiment. A modified sawtooth voltage is applied between opposite ends of the symmetrical system so as to drive the insulated hemisphere and its associated guard negative with respect to the reference end of the instrument. 


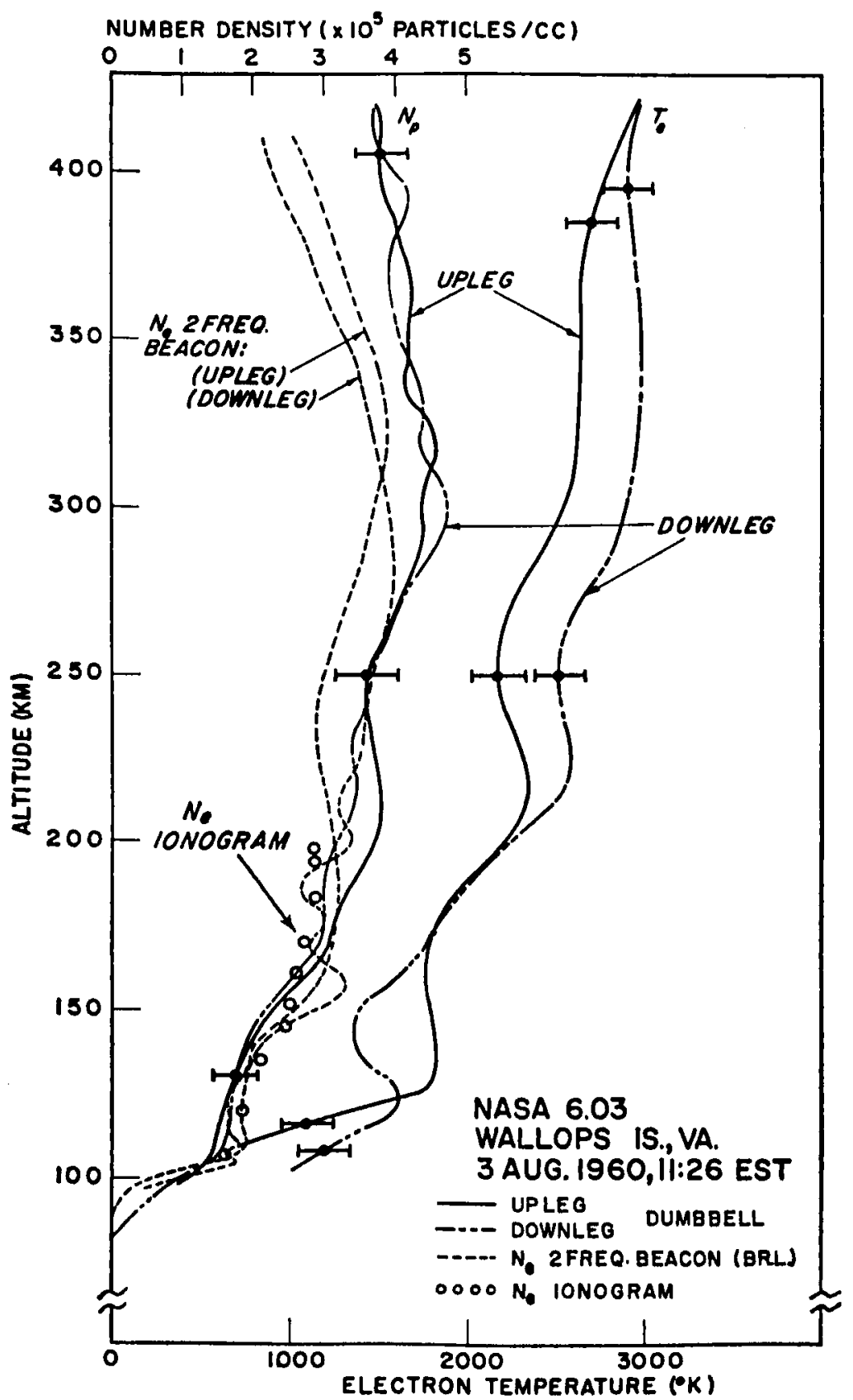

Fig. 2. Final ionospheric data from NASA 6.03 (disturbed day). The electron temperature $T$. and the positive ion density $N$, derived from the Dumbbell volt-ampere characteristica are shown. The error flags represent both sprend in the data and possible errors in the theory. Also shown are the electron densities $N$. measured by the two-frequency beacon carried with the rocket (courtesy W. Berning) and those derived from ground-based ionosonde records. 
nighttime data that has not been published previously.

\section{The Measurement Techinique}

The direct measurement technique employs a dumbbell-shaped symmetrical bipolar probe that is ejected from the rocket vehicle at the base of the ionosphere, rises to several hundred kilometers, and returns to earth. While it is in the ionosphere, a sawtooth voltage is applied to a hemispherical collector, and the resulting currents are measured and telemetered to receiving stations where the data are recorded for later analysis in terms of the electron temperature and positive ion density, point by point along the flight path. Figure 1 shows the measurement circuit. The magnitude of the recorded current is proportional to the local ion density $N_{p}$, and the shape or curvature of each volt-ampere characteristic is related to temperature of the

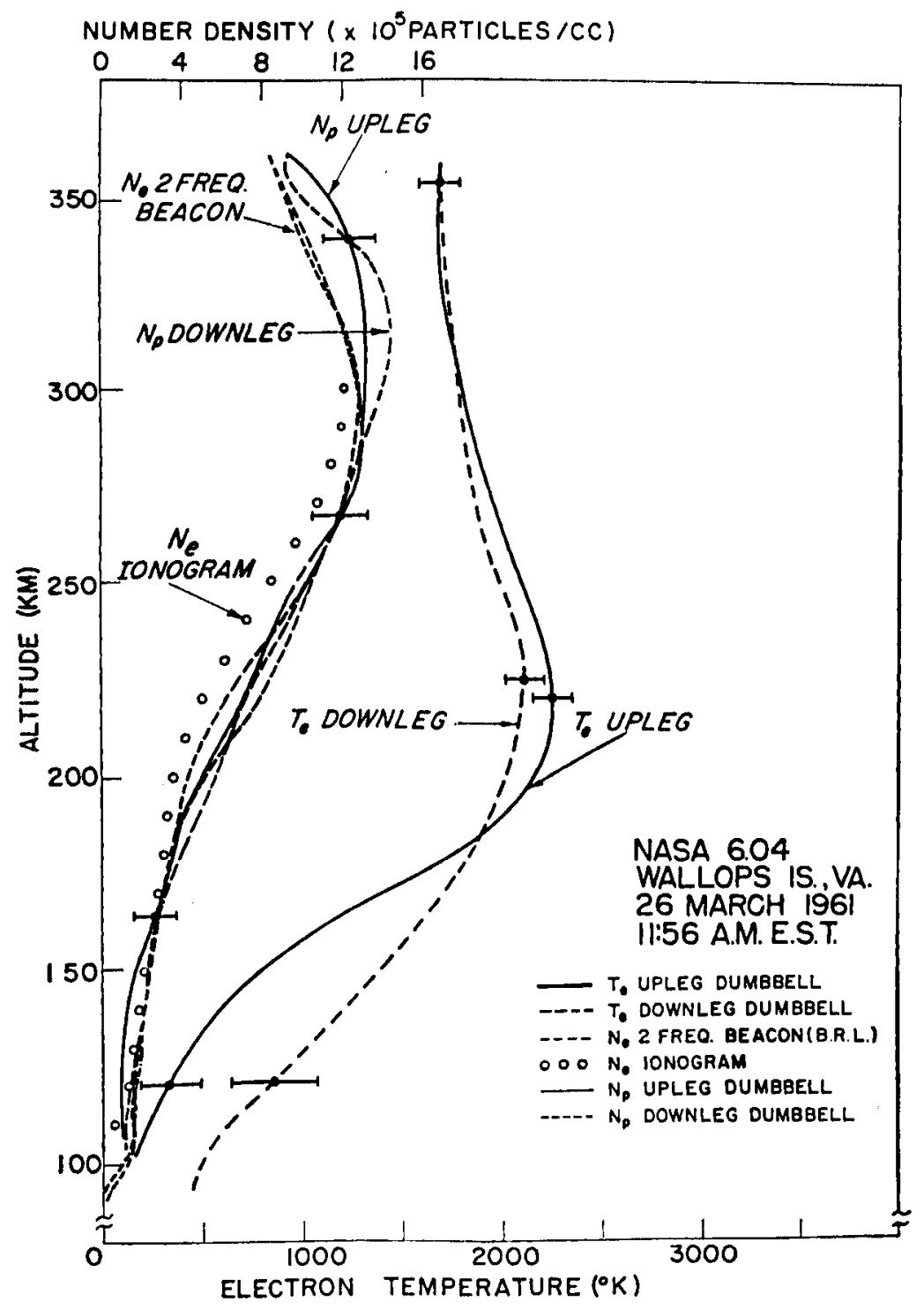

Fig. 3. Final ionospheric data from NASA 6.04 (quiet day). The electron temperature $T$. and the positive ion density $N_{p}$ derived from the Dumbbell data are shown with the $N$, values from the two-frequency beacon and ionosonde. 
ambient electrons $T_{\text {. }}$. Details of the measuremont theory and the methods of data analysis are documented elsewhere [Spencer et al., 1962; Ilocoy and Brace, 1961; Brace, 1962].

\section{Final Data from Daytime Wallors Island Flights}

The complete data from NASA flights 6.03 and 6.04 (previously reported in preliminary form) are shown in Figures 2 and 3 , respectively. Also shown are the electron density profiles derived from a two-frequency beacon experiment (courtesy of Warren Berning, BRL), which remained with the vehicle after Dumbbell ejection, and the electron densities derived from the ground-based ionosonde records (courtesy of J. W. Wright, NBS). The combincd effects of spread in the individual data points and our estimate of the uncertainty in the theory are indicated by the error flags. The uncertainty in the theory tends to be systematic and does not change the shape of the profiles. These midday measurements were carried out about 8 months apart at the same midlatitude launch site $\left(38^{\circ} \mathrm{N}\right)$; howcver, the ionospheric conditions at the times of launch were quite different. Magnetic storms were reported by several observers [Lincoln, 1961] during the days preceding the launch of NASA 6.03 , July 29 to August 1, 1960. Although the launch date was not listed as disturbed, the severe depression of the $F_{\text {a }}$ maximum, readily apparent in both the electron and ion density profiles, undoubtedly was part of the so-called 'after effect' of an ionospheric storm [Ratcliffe and Weekes, 1960]. The period immediately preceding the launching of NASA 6.04, however, was unusually quict magnetically. In the discussion, the data from these flights will be considered in terms of the degree of disturbance of the ionosphere.

\section{Nightтime Midlatitude Ionospheric Data}

The most recent launching of the Dumbbell series was carried out at Wallops Island shortly before midnight on December 21, 1961. At an altitude of $86 \mathrm{~km}$ the clamshell nose cone opened and ejected the instrument into a region having an ion density $N_{p}$ below its limit of resolution

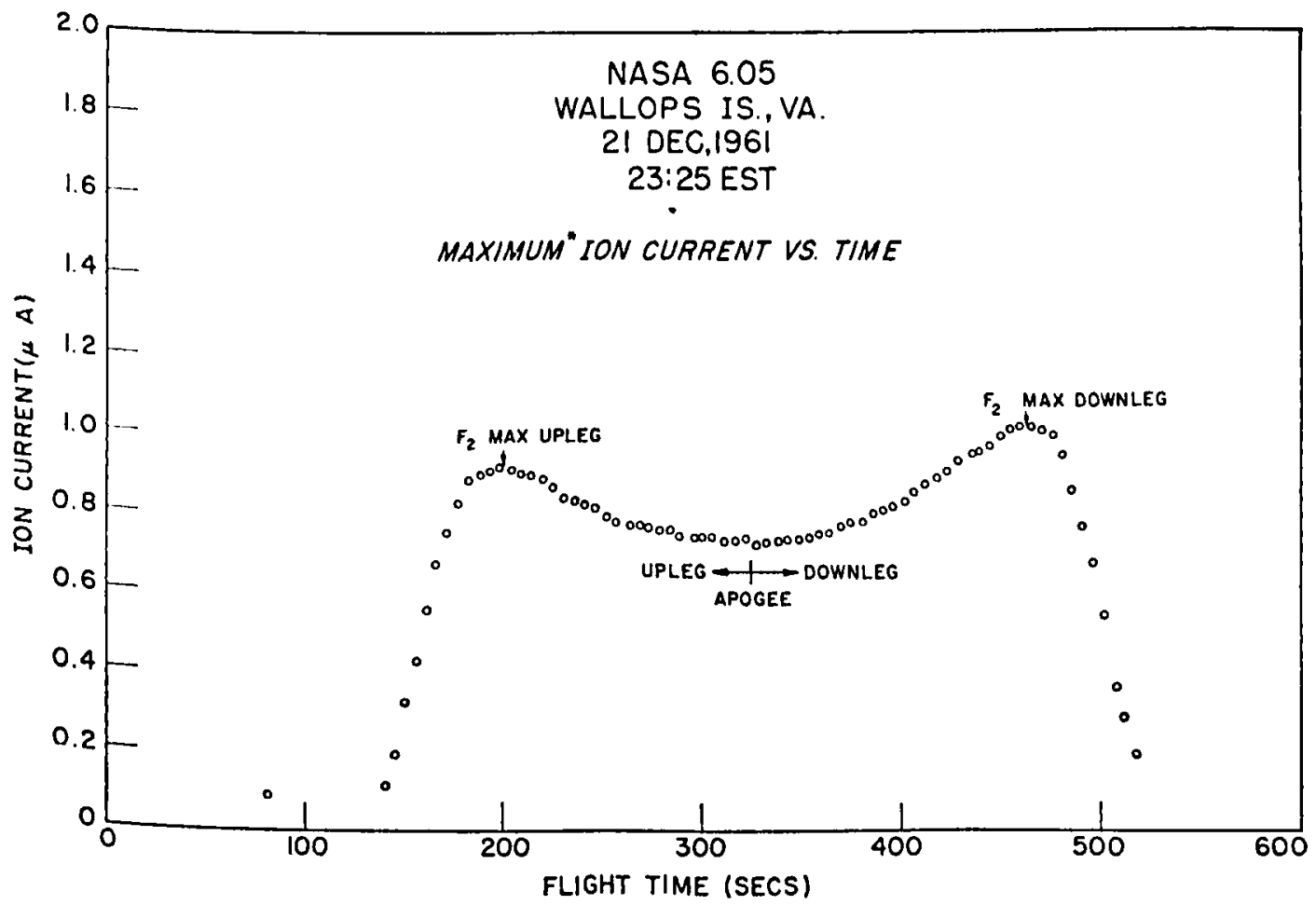

Fig. 4. Ion current data from NASA 6.05. Maximum ion current refers to the hemisphere current measured at the maximum applied voltage $(-3$ volts $)$. 


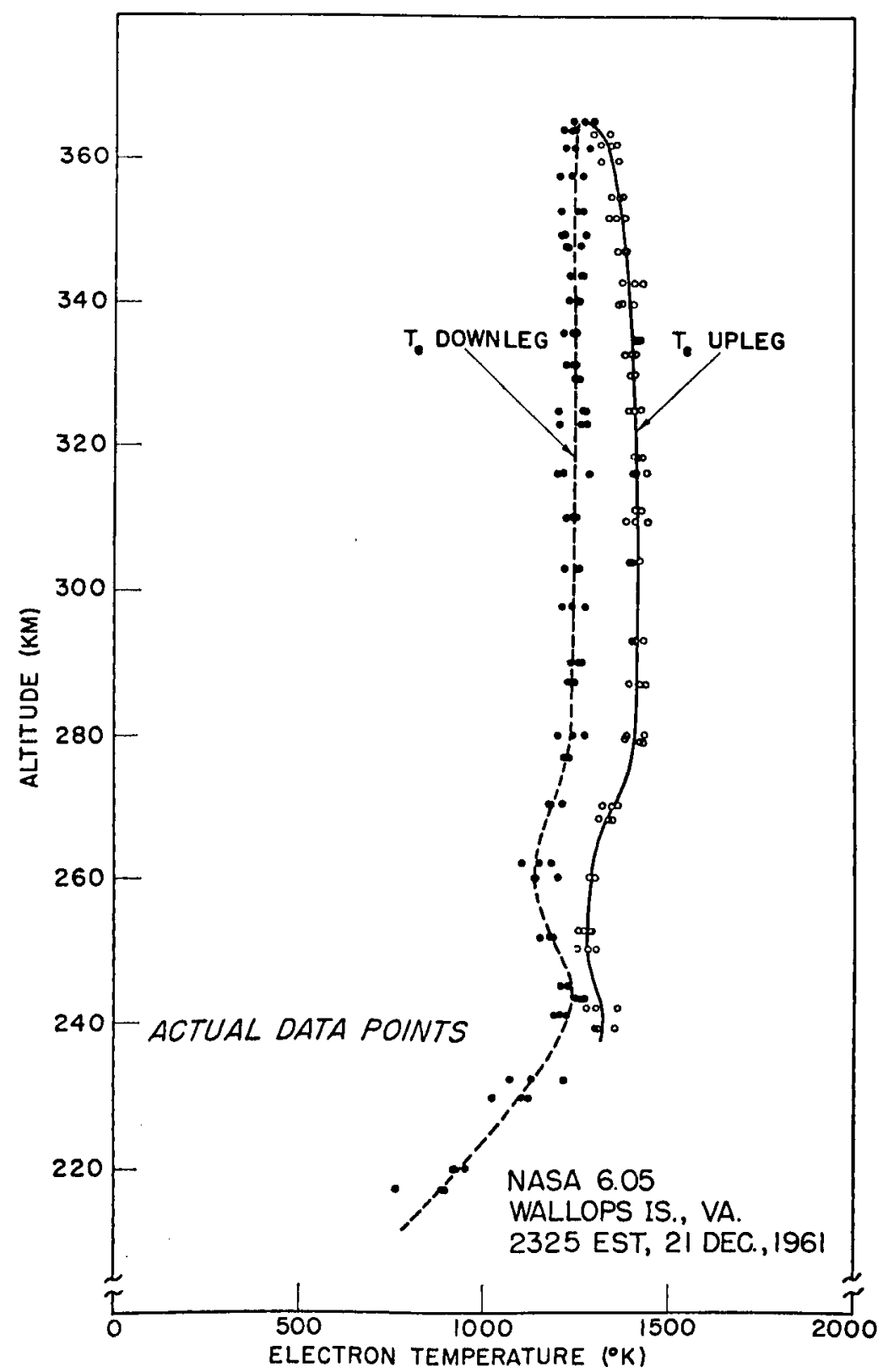

Fig. 5. Actual electron temperature data points from NASA 6.05 flight. At selected altitude intervals, three consecutive current characteristics were analyzed for electron temperature. The open and closed circles represent the upleg and downleg values, respectively.

$\left(N_{p}<1 \times 10^{\mathrm{s}} \mathrm{ions} / \mathrm{cc}\right)$. A small nighttime $E$ region was detected between 95 and $105 \mathrm{~km}$ above which the current again fell below the detectable limit. $F$-region currents were first detected above $204 \mathrm{~km}$ and were well resolved through apogee of the flight, as shown in Figure 4 , which is a plot of the ion current versus flight time. The times of $F_{2}$ passage are clearly evident at $200 \mathrm{sec}$ and 460 sec. These values of ion current were used in the appropriate equations [Hoegy and Brace, 1961] to calculate the ion density values shown in Figure 6. The $E$-region values of $N_{p}$ were near the limit of detection but are estimated to be accurate within a factor of 2 . 
The accuracy at higher altitudes is indicated by the error flags shown. Also shown are the electron density values $N$. derived from an ionogram recorded at Wallops Island during the flight. The low electron density made the ionogram anulysis difficult, particularly in converting from virtual height to actual height. This is evident from the difference in the altitude of the $F_{2}$ maximum indicated by the ionosonde data (350 $\mathrm{km})$ and by the probe data. 'The actual altitude of the maximum $(310 \mathrm{~km})$ is best derived from the ion current data shown in Figure 4. Note that the maximums in the $N_{p}$ profiles are less pronounced than those in the current data owing to the correction for probe velocity in the density calculation.

Above $240 \mathrm{~km}$ on ascent and $220 \mathrm{~km}$ on deseent the charge densities, and therefore the currents, were large enough to allow precise extraction of the electron current from the voltampere characteristics and thus permit analysis of the data in terms of the electron temperature of the surrounding plasma. Figure 5 shows the actual temperature data points, each represent-

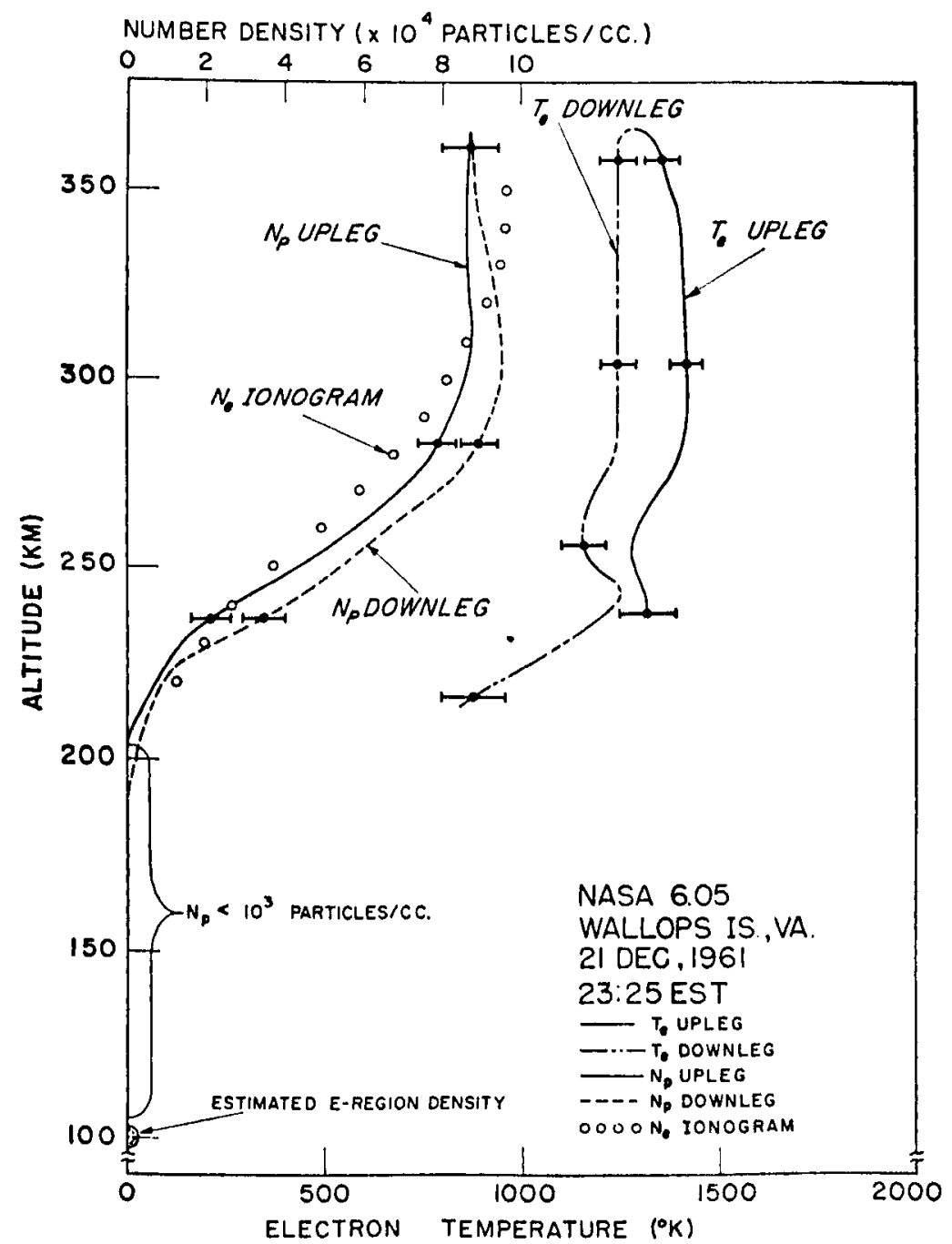

Fig. 6. Ionosphere data from NASA 6.05 (nighttime). $T$. and $N_{\text {p }}$ valuns from the Dumbbell are plotted with the ionosonde values of $N_{\text {. }}$. Between 105 and about $200 \mathrm{~km}$ the ion currents were too small to resolve. The $E$-region values of $N_{\text {p }}$ were $4 \times 10^{3} / \mathrm{cc}$ on the upleg and $2 \times 10^{3} / \mathrm{cc}$ on the downleg. 
TABLE I

TABULATED DUMBBELL PROBE DATA

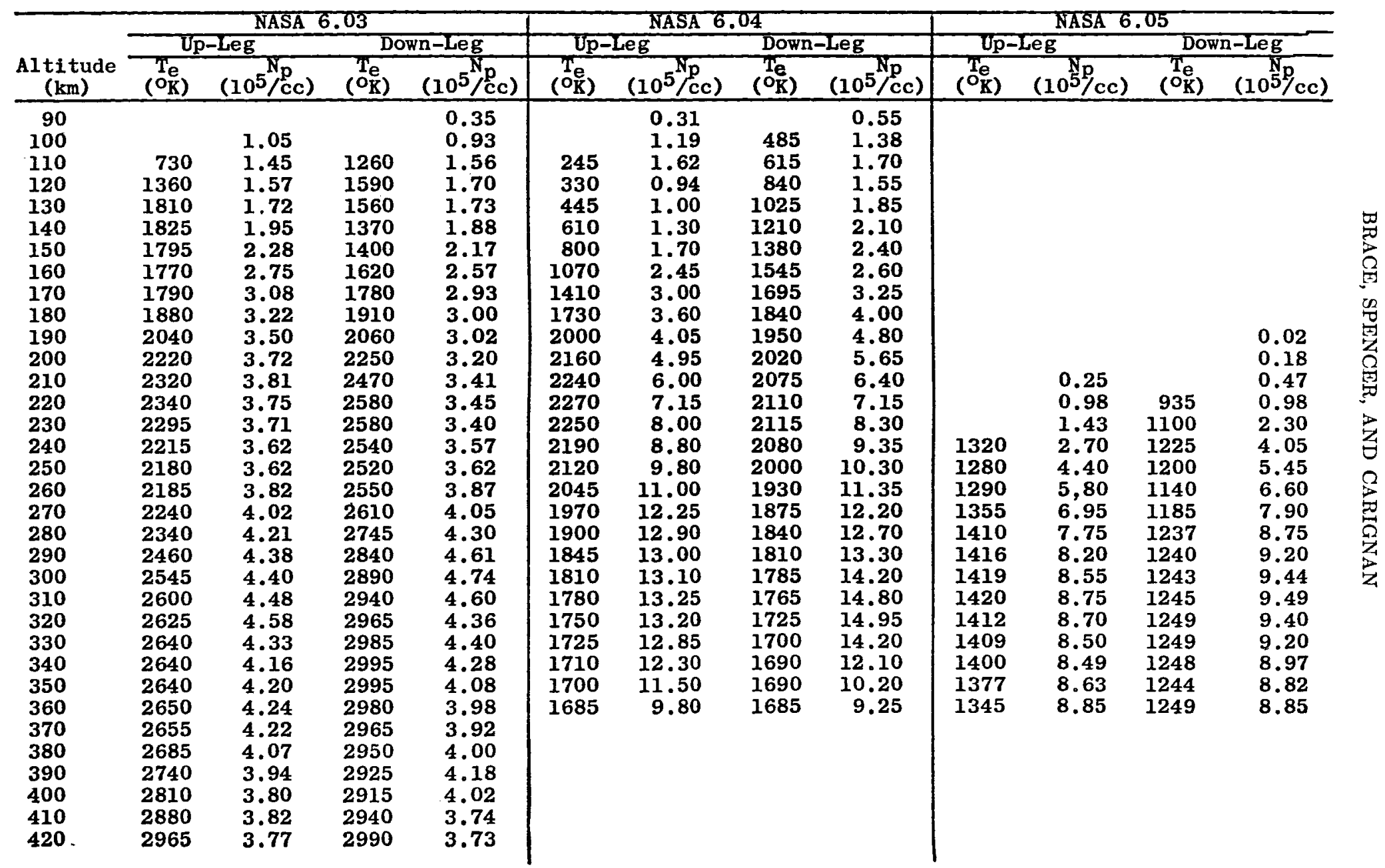


ing a single probe characteristic, used to arrive at the $T$. profile shown in Figure 6.

The data from NASA 6.03, 6.04, and 6.05 are tabulated at $10-\mathrm{km}$ intervals in Table 1 .

\section{Discussion}

\section{The Quiet Ionosphere (NASA 6.04)}

It is interesting to compare the electron temperatures measured in the quiet ionosphere with those calculated by Hanson [1962] and Dalgarno et al. [1962] (Figure 7). The CIRA 1961 average maximum gas temperature profile is shown for reference. As was mentioned earlicr, both authors based their computations on rocket measurements of solar EUV flux and the important cnergy transfor mechanisms, and both predicted a region of thermal nonequi- librium in the $F$ region similar to that evident in the electron temperature data from this flight in the quict ionosphere. Dalgarno's temperatures are shown as a range of values (hatched area) corresponding to his selection of combinations of the two most probable energy storage mechanisms, namely, vibrational excitation of molecular nitrogen and excitation to metastable states of atomic oxygen. This stored energy is later returned in part to the electrons, thereby further increasing their temperature above that of the neutral particles.

The agreement between these theoretical and experimental temperatures demonstrates that solar EUV alone is an adequate energy source to produce the observed electron heating in the quict daytime ionosphere at midlatitudes. If other heat sources are present under these con-

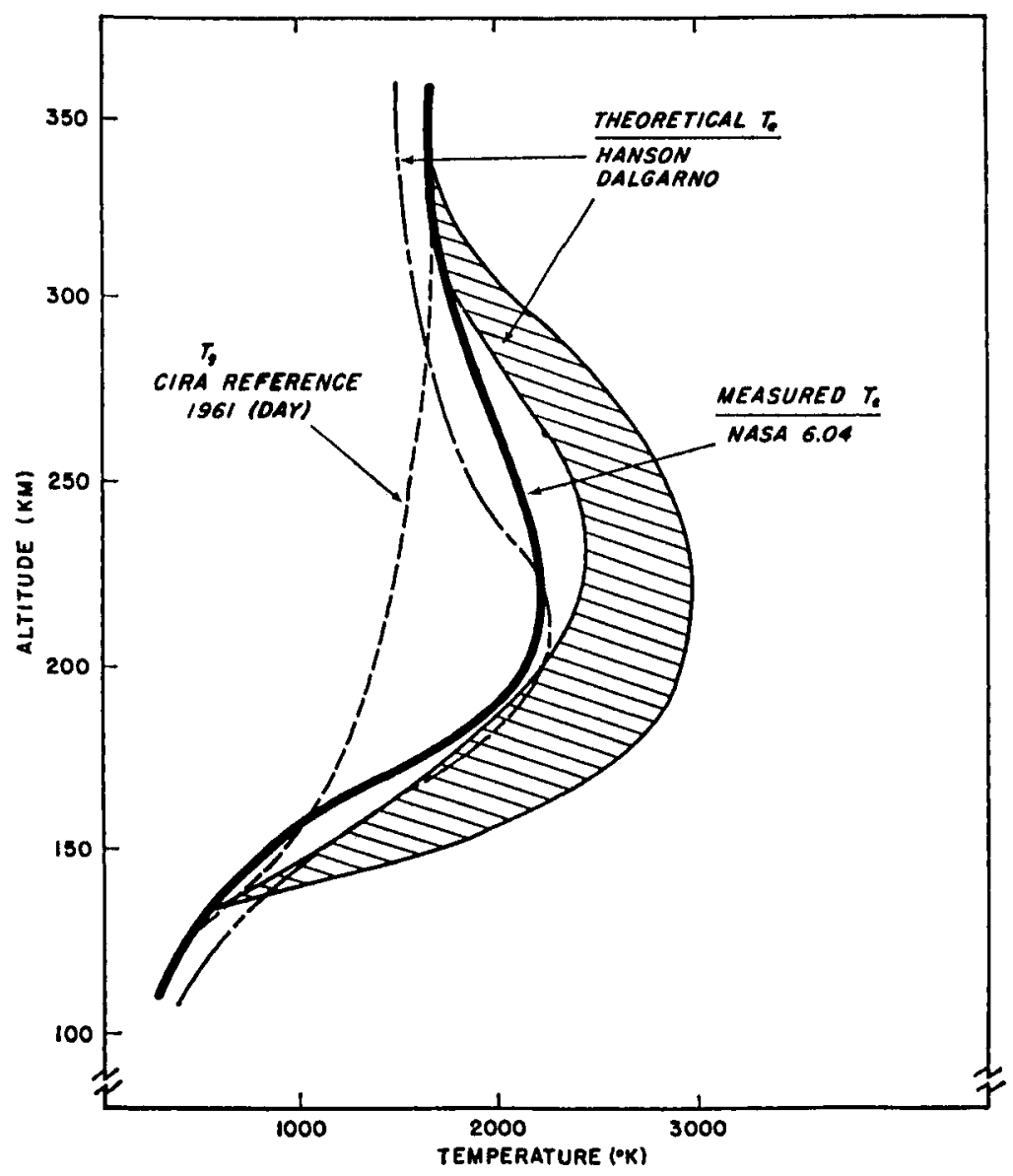

Fig. 7. Comparison of mensured and theoretical values of electron temperature in the quiet daytime ionosphere. 
ditions, their effects must be masked by the uncertainty of the neutral temperature existing at the time of the electron temperature measurement.

\section{The Disturbed Ionosphere (NASA 6.09)}

The clearly different character of the disturbed ionospheric temperature profile becomes evident when it is compared with the quiet

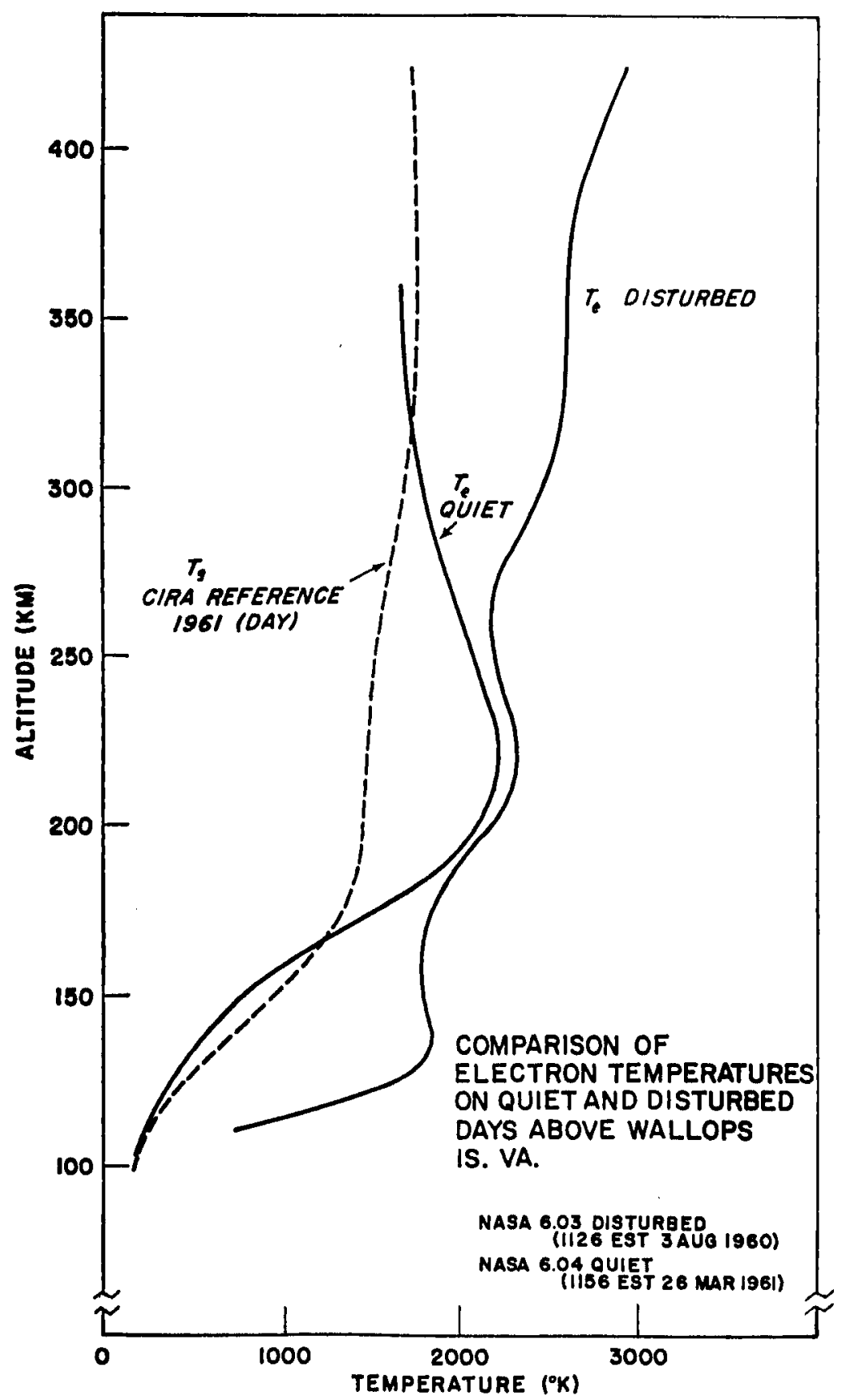

Fig. 8. Comparison of electron temperatures in the quiet and disturbed midlatitude ionosphere with the reference gas temperature. 
ionosphere data (Figure 8). The gross effect is an increased electron temperature in both the $E$ and $F_{2}$ regions with apparently little effect in the $F_{1}$ region. The steep temperature gradient between 105 and $125 \mathrm{~km}$, accompanied by a higher than normal $E$-region density (Figure 2), is evidence of an additional energy input at these altitudes. It is not yet clear, however, whether the higher temperatures in the $F_{2}$ region were caused by an increased heat input at these altitudes or by sharing the existing EUV energy among the reduced number of ambient electrons there under these conditions.

\section{The Nighttime Ionosphere (NASA 6.05)}

Possibly the most unexpected feature of the nighttime temperature profiles (Figure 6) is the temperature difference of the regions traversed on ascent and descent. Although the downleg values are in agreement with the 1961 CIRA reference gas temperatures, they are some 5 to 15 per cent lower than the upleg values. Both profiles are essentially isothermal with altitude in the $F_{\mathrm{s}}$ region, in agreement with heat conduction theory [Nicolet, 1960]. Thus we interpret the change in temperature occurring near apogee as evidence of a horizontal gradient traversed by the instrument in its largely horizontal path through the $F_{\mathrm{a}}$ region.

(It is important to note that the nature of the Dumbbell experiment permits us to make detailed comparison between upleg and downleg data with some assurance. This is true for two reasons; first, the ejection of the device carries it sufficiently far ahead of the rocket, its exhaust gases, and its charged particle wake to eliminate possible perturbing effects on the collected currents; second, the tumbling motion of the device permits the collectors to experience identical orientation and velocity effects at equivalent altitudes on ascent and descent. Thus the ejection concept and tumbling motion permit greater confidence that observed differences in upleg and downleg data are due to natural atmospheric variations rather than experiment contamination or perturbations in the

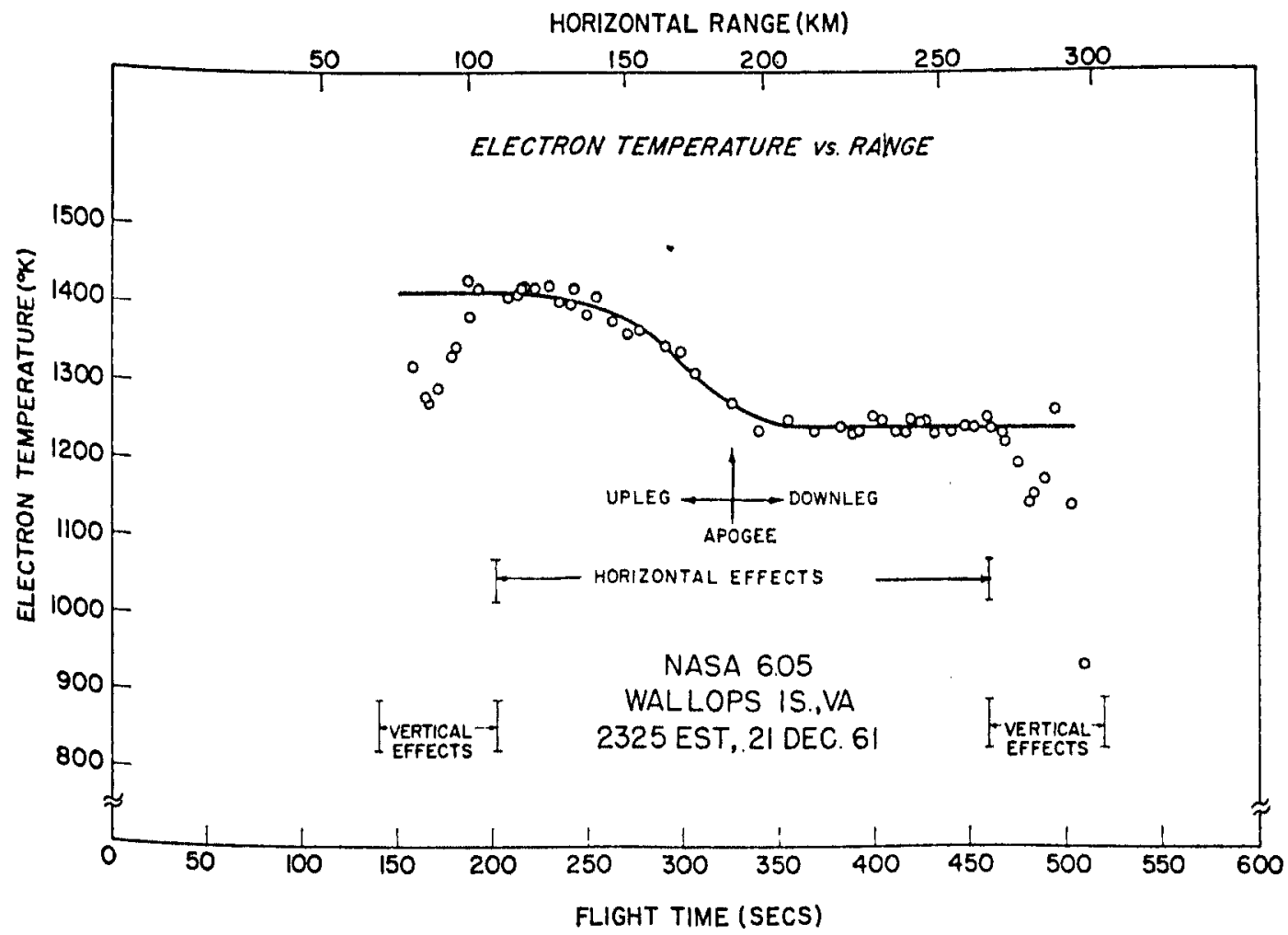

Fig. 9. Plot of electron temperature versus horizontal range. This reveals the temperature gradient, encountered near apogee of NASA 6.05, as a horizontal gradient. 
mode of current collection. Periodic inflight calibration of the current channels, using the sawtooth voltage and a known resistance, provide added assurance that any changes in measured parameters are not caused by changes in the electrical characteristics of the measurement system.)

To investigate further the nature of the gradient, the temperature data points were replotted versus flight time or horizontal range (Figure 9). Each point represents an average of the groups of three points of Figure 5. Here it is clear that the entire change in temperature occurred over a horizontal range of $75 \mathrm{~km}$. Since this corresponded to only a $25-\mathrm{km}$ range in altitude, the gradient must have been primarily horizontal in nature.

A certain amount of horizontal gradient will normally result from the diurnal temperature variation experienced by the instrument as its eastward horizontal motion and the elapsed time of flight combine to change its local time by approximately 30 minutes. However, currently held concepts about the nature of the

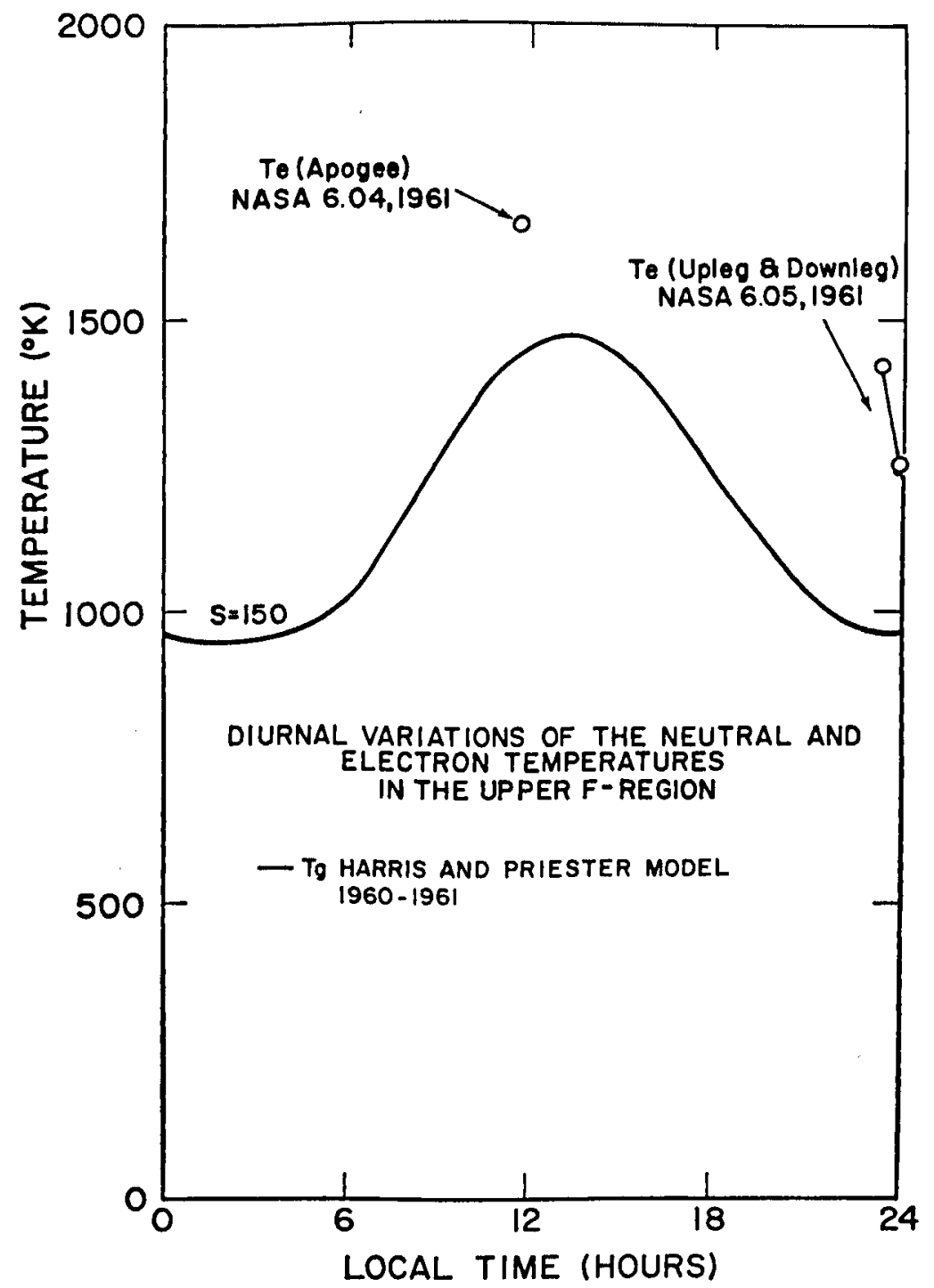

Fig. 10. Comparison of neutral temperatures [Harris and Priester, 1962] and electron temperature diurnal variation. 
normal diurnal variation of neutral particle temperature are not compatible with the degree of temperature decrease observed. For example, the Ilarris and Priester [1962] model (Figure 10) suggests that a decrease in gas temperature of only a few per cent should be expected in the half-hour period shortly before midnight. The upleg and downleg values of NASA 6.05 and the apogee value of NASA 6.04 are plotted for comparison with the theoretical model for a $10.7-\mathrm{cm}$ flux of $150 \times 10^{-23} \mathrm{~W} /\left(\mathrm{m}^{2} \mathrm{c} / \mathrm{s}\right)$, which corresponds generally to the levels of solar activity in 1960 and 1961 .

If we assume that thermal equilibrium existed at apogee of the NASA 6.04 daytime flight, as the approach of the temperature profile to an isothermal suggests, and accept the current belief that thermal equilibrium exists at night (NASA 6.05), we are tempted to infer from Figure 10 that the actual gas temperatures are normally somewhat higher than the Harris and Priester models suggest, particularly at night. An alternate conclusion is that thermal equilibrium may not invariably exist in the nighttime ionosphere. It is conceivable, for example, that particle fluxes traveling along geomannetic field lines could selectively hent the electrons and raise their characteristic temperature somewhat above that of the neutral particles. A similar degree of particulate heating would not be as noticcable in the quiet daytime ionosphere (Figure 3), since it would be masked by solar EUV heating. If the particle flux were inhomogeneous and time-varying, different degrees of nonequilibrium would exist over different parts of the earth, and horizontal gradients in the electron temperature would result. Furthermore, the geomagnetic field at middle and high latitudes inhibits the horizontal conduction of energy between electrons in neighboring regions; thus horizontal temperature gradients, once established, would be maintained by a relatively small heat input.

Hanson and Johnson [1961] have shown that, in the region above $300 \mathrm{~km}$ where the energy of the thermal electrons is coupled primarily to the ions, the difference between the electron and gas temperature is given approximately by the expression

$$
T_{e}-T_{0}=2.1 \times 10^{\circ} Q T_{\circ}^{3 / 2} / n_{a}^{2}
$$

where $Q$ is the input energy in the units of $\mathrm{ev} / \mathrm{cm}^{3} / \mathrm{sec}$. Clearly the horizontal variation of $T$. depends not only on the variations in $Q$ but on the variations in $T_{0}$ and $n$, as well. Note that the degree of nonequilibrium is particularly sensitive to $n_{e}$, since it enters as the square. The 10 per cent difference in the ascent and descent values of charge density, evident in Figure 6, would alone induce a 20 per cent difference in electron temperature, somewhat greater than was actually observed. It is significant that the magnitude of $n$. observed on both ascent and descent of NASA 6.05 were well below the normal midnight values. This would contribute to a larger value of $\left(T_{\bullet}-T_{\natural}\right)$ if an energy flux were present.

A second unexpected feature of the nighttime temperature profiles is the ' $S$ ' shaped variation between 280 and $220 \mathrm{~km}$ for which no geophysical explanation is offered. The currents were well resolved through most of this altitude region, and we are not aware of any instrumental errors that could produce this effect.

\section{Comparison of Midlatitude and Auroral Zone Electron Temperatures}

Other significant aspects of ionospheric behavior become apparent when the Wallops Island data are plotted with the temperature data from two flights at Ft. Churchill reported earlier (Figure 11). Latitude effects are apparent in the comparison of the Churchill $\left(59^{\circ}\right)$ data with the daytime Wallops Island $\left(38^{\circ}\right)$ data, and the solar-cycle variation is evident in the generally decreasing temperatures found on successive daytime flights.

Latitude effects. The consistently higher electron temperature observed in the auroral zone, particularly in the $E$ and $F_{2}$ regions, and the gross dissimilarity of the auroral zone and the quict midlatitude profiles are interpreted as evidence of a significant additional energy source that may be more important than solar EUV in these regions of the auroral zone ionosphere. The highly variable nature of the NASA 6.01 temperature data is attributed to the spread $F$ condition that existed.

An interesting similarity in all the daytime profiles is the tendency for the temperature in the $F_{1}$ region (approximately $200 \mathrm{~km}$ ) to be essentially identical under a variety of ionospheric conditions at both latitudes $\left(59^{\circ} \mathrm{N}\right.$ and $38^{\circ} \mathrm{N}$ ). This is in the altitude range where solar 


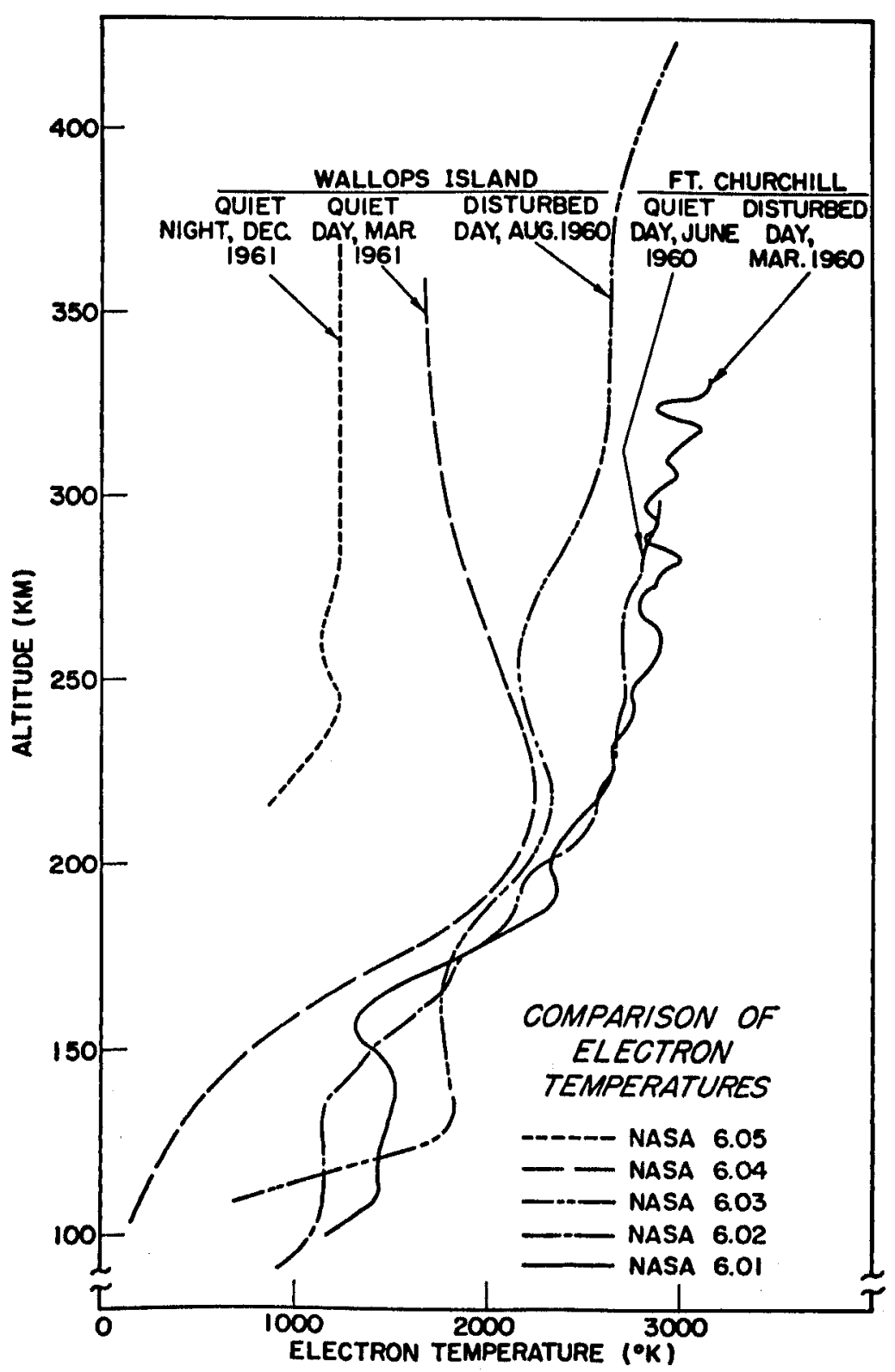

Fig. 11. Composite of electron temperature from the five Dumbbell flights of the NASA series carried out between March 1960 and December 1961 .

EUV absorption is greatest and is considered evidence that EUV remains the most important source of energy in the $F_{1}$ region, even under magnetically disturbed and auroral zone conditions.

Solar activity. The effect of decreasing solar activity is apparent in the monotonically decreasing electron temperature at $F_{1}$-region altitudes on successive flights as the sunspot cycle proceeds toward its minimum. The fact that this correlation does not carry over to the $E$ region temperatures may be related to other 
heating mechanisms which become important in this region at higher latitudes and under magnetically disturbed conditions.

\section{Conclugions}

We conclude on the basis of the data presented here and current ionosphere theory that:

1. Solar extreme ultraviolet flux is the dominant heat source for the quiet daytime $F$ region at midlatitudes $\left(50^{\circ}\right.$ magnetic latitude).

2. An additional heat source, probably corpuscular, is effective in heating electrons in the $E$ and possibly the $F_{2}$ regions of the auroral zone and disturbed midlatitude ionosphere. However, the constant electron temperature at $200 \mathrm{~km}$, in both the auroral and midlatitude ionosphere, shows that EUV remains the dominant heat source in the $F_{1}$ region.

3. The 'after effects' of a magnetic storm (the decreased $F_{2}$-region density and the increased $F_{z^{-}}$and $E$-region electron temperature) continue for at least a day after the magnetic indices have returned to normal.

4. Particle fluxes may selectively heat the electrons in the nighttime $F$ region and produce small but variable degrees of thermal nonequilibrium.

The evidence for conclusion 1 is the agreement between experimental electron temperatures (NASA 6.04) and theoretical models of lectron temperature based exclusively on solar EUV heating. The experimental evidence for conclusion 2 is shown in Figure 11, and conclusion 3 is based on Figures 2 and 8 . Figures 9 and 10 are considered evidence for conclu$\operatorname{sion} 4$.

Perhaps investigators, more familiar with particular aspects of ionospheric behavior, will uncover relationships in these data that have escaped us or will suggest alternate interpretations of the effects noted here.

It is not yet clear from these and other reported ionospheric data that the electron temnerature in the ionosphere is related in any simple way to the gas temperature, except possibly under very quiet conditions. Though the electron temperature profiles from the single flight in the quiet midlatitude ionosphere appear to validate the theoretical approaches of Hanson [1962] and Dalgarno et al. [1962] for the quiet ionosphere, the data from the three other day time flights demand other heat sources and lead us to suspect that a quiet ionosphere may have been so rare in the 1960-1961 period as to be considered anomalous.

Since it is the difference between the neutral particle and electron temperatures that permits transfer of much of the solar encrgy into the high neutral atmosphere, we would expect the degree of thermal nonequilibrium to be strongly dependent on the solar conditions and the relative contribution of the various forms of energy input at particular latitudes and times of day. Thus the electron temperature can be expected to be a sensitive indicator of the kinds of physical processes occurring in the themosphere. Additional measurements which are planned will be useful in evaluating new theories being evolved to describe the regions and degree of thermal nonequilibrium in the ionosphere for a wider range of conditions.

Acknowledgments. We are indebted to W. W. Berning of the Ballistic Research Iaboratory for the two-frequency beacon values of electron density for NASA flights 6.03 and 6.04 , and to J. W. Wright of the National Bureau of Standards for the ionosonde values of electron density for all flights.

The series of measurcments reported here and the development of the theory of the Dumbbell probe were carried out at the University of Michigan with the support of the National Acronautics nnd Space Administration (contract NASw-139). Early developmental work during the International Geophysical Year was supported by the Air Force Cambridge Research Laboratory and the Ballistic Resenrch Iaboratory.

\section{References}

Bnuer, S. J., and R. E. Bourdenu, Upper atmosphere temperatures derived from charged particle observations, J. Atmospheric Sci., 19, $218,1962$.

Brace, I. H., The dumbbell ionosphere probe; ionosphere data, Sci. Rept. JS-s, Univ. Mich. ORA Rept, OB590-11-F, September 1962.

Brace, I. H., N. W. Spencer, G. R. Curignan, and W. Hoegy, Paper presented at the URSI-IRE meeting, Wnshington, D. C., May 1962.

Dalgarno, A., M. F. McElroy, and R. J. Moffett, Planetary aeronomy, 6, Electron temperatures in the ionosphere, Geophys. Corp. Am. Tech. Rept. 62-11-N, November 1962.

Evans, J. V., Diurnal temperature variations of the $F$ region, J. Geophys. Res., 67, 4914-4920, 1962.

Hanson, W. B., Electron temperatures in the upper atmosphere, Space Research, Proc. Intern. 
Space Sci. Symp., Brd, Washington, 1060, edited by W. Priester, pp. 282-302, North-Holland Publishing Company, Amsterdam, 1962.

Hanson, W. B., and F. S. Johnson, Electron temperatures in the ionosphere, paper presented at Tenth International Astrophysical Colloquium, Liège, Belgium, 1961.

Hanson, W. B., and D. D. MeKibbin, An ion trap measurement of the ion concentration profile above the $F_{3}$ peak, $J$. Geophys. Res., 66, 1667$1671,1961$.

Harris, I., and W. Priester, Theoretical models for the solar cycle variation of the upper atmosphere, J. Geophys. Res., 67, 4585-4591, 1962.

Hocgy, W. R., and L. H. Brace, Sci. Rept. JS-1, Univ. Mich. ORA Rept. 03509-5-S, September 1961.

Jackson, J. E., and S. J. Bauer, Rocket measure- ment of a daytime electron density profile up to 620 kilometers, J. Geophys. Res., 66, 3055$3057,1961$.

Lincoln, J. V., Geomagnetic and solar data, J. Geophys. Res., 66, 311, 1961.

Nicolet, M., Physics of the Upper Atmosphere, chapter 2, Academic Press, New York, 1960.

Ratcliffe, J. A., and K. Weekes, Physics of the Upper Atmosphere, chapter 9, Academic Press, New York, 1960.

Spencer, N. W., L. H. Brace, and G. R. Carignan, Electron temperature evidence for nonthermal equilibrium in the ionosphere, J. Geophys. Res., $67,157-175,1962$.

(Manuscript received May 16, 1963; revised July 19, 1963.) 